\title{
Weather Conditions and Outdoor Fall Injuries in Northwestern Russia
}

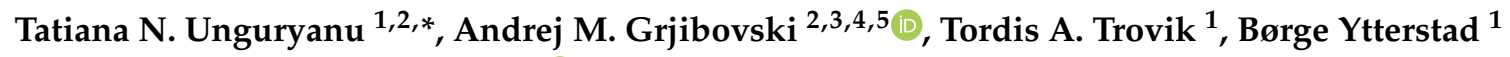 \\ and Alexander V. Kudryavtsev ${ }^{1,2}$ D \\ 1 Department of Community Medicine, UiT The Arctic University of Norway, N-9037 Tromsø, Norway; \\ tordis.a.trovik@uit.no (T.A.T.); boergey@online.no (B.Y.); ispha09@gmail.com (A.V.K.) \\ 2 Arkhangelsk International School of Public Health, Troitsky Ave., 51, Northern State Medical University, \\ 163000 Arkhangelsk, Russia; andrej.grjibovski@gmail.com \\ 3 Al-Farabi Kazakh National University, Almaty 050040, Kazakhstan \\ 4 West Kazakhstan Marat Ospanov State Medical University, Aktobe 030019, Kazakhstan \\ 5 Sechenov First Moscow State Medical University (Sechenov University), 119991 Moscow, Russia \\ * Correspondence: tatyana.n.unguryanu@uit.no or unguryanu_tn@mail.ru
}

Received: 10 July 2020; Accepted: 18 August 2020; Published: 21 August 2020

\begin{abstract}
This study aimed to investigate associations between the weather conditions and the frequency of medically-treated, non-fatal accidental outdoor fall injuries (AOFIs) in a provincial region of Northwestern Russia. Data on all non-fatal AOFIs that occurred from January 2015 through June $2018(N=1125)$ were extracted from the population-based Shenkursk Injury Registry (SHIR). Associations between the weather conditions and AOFIs were investigated separately for the cold (15 October-14 April) and the warm (15 April-14 October) seasons. Negative binomial regression was used to investigate daily numbers of AOFIs in the cold season, while zero-inflated Poisson regression was used for the warm season. The mean daily number of AOFIs was 1.7 times higher in the cold season compared to the warm season ( $1.10 \mathrm{vs.} 0.65$, respectively). The most typical accident mechanism in the cold season was slipping $(83 \%)$, whereas stepping wrong or stumbling over something was most common $(49 \%)$ in the warm season. The highest mean daily incidence of AOFIs in the cold season (20.2 per 100,000 population) was observed on days when the ground surface was covered by compact or wet snow, air temperature ranged from $-7.0^{\circ} \mathrm{C}$ to $-0.7^{\circ} \mathrm{C}$, and the amount of precipitation was above $0.4 \mathrm{~mm}$. In the warm season, the highest mean daily incidence (7.0 per 100,000 population) was observed when the air temperature and atmospheric pressure were between $9.0^{\circ} \mathrm{C}$ and $15.1{ }^{\circ} \mathrm{C}$ and 1003.6 to $1010.9 \mathrm{hPa}$, respectively. Along with local weather forecasts, broadcasting warnings about the increased risks of outdoor falls may serve as an effective AOFI prevention tool.
\end{abstract}

Keywords: outdoor fall injuries; injury registry; weather conditions; Shenkursk

\section{Background}

Falls and fall-related injuries represent a serious health problem worldwide, especially in regions with a cold climate [1-3]. In 2015, age-standardized mortality rates from accidental falls in the Nordic countries and Russia were 1.3 times higher than those for the entire World Health Organization European Region (5.2 per 100,000) [4,5]. Falls are accountable for the largest shares of injury-related deaths and hospitalizations among older adults $[6,7]$, and they are also associated with substantial healthcare expenditures [2,8].

In Northern geographic regions, outdoor falls occur more frequently than indoor falls. Studies carried out in Norway, Sweden, the UK, the USA, and Canada have demonstrated that between 55\% 
and $62 \%$ of falls among middle-aged and older adults occur outdoors [2,9-12]. Streets, sidewalks, and curbs are the most common locations of outdoor falls [7,11,13]. Compared to indoor falls, outdoor falls are associated with a higher level of physical activity [11,14]. A review of prospective observational studies has shown that outdoor falls are more common in elderly people with better health-related parameters like lower body mass index, higher walking speed, and fewer diseases [15]. Moreover, the number of outdoor falls is influenced by environmental hazards, surface irregularities, weather and its seasonal variations $[2,11,16,17]$.

The incidence of fall-related injuries is characterized by the seasonal variation in different geographic regions, including countries with cold climate (Canada, Sweden, Finland, and Norway) $[3,13,17,18]$ and countries with warm and subtropical climate (Taiwan, Spain, Iran, and Hong Kong) [19-22]. Winter-related environmental conditions (low air temperature, snowfalls, and darkness) can cause slipperiness and increased dangerousness of sidewalks and streets [23,24]. Exposure to slippery ground surfaces, such as those covered with ice, melting ice, snow-covered ice, melting snow, and compressed snow is a common attribute of winter-time falls [16,23-25].

The weather conditions of the Russian North can be described as severe, with long, cold winters, sometimes heavy snowfalls, and very strong winds. However, studies investigating the association between weather conditions and outdoor fall injuries at the population level have not been carried out in this region. Knowledge of this association could be used to develop more effective prevention through the creation of risk-reducing environments, as well as through raising population awareness about the risk factors for falls $[2,11]$.

The aim of the study was to investigate associations of weather conditions and the frequency of medically-treated, non-fatal accidental outdoor fall injuries (AOFIs) in a provincial region of Northwestern Russia. An accidental fall injury was defined as "inadvertently coming to rest on the ground, floor or other lower level" (International Classification of Diseases, Revision 10 [ICD-10] codes W00-19) [26]. An outdoor fall was defined as "one occurring outside a dwelling or building" [7,11,14].

\section{Methods}

\subsection{Study Area}

The present study was conducted in the Shenkursk District of the Arkhangelsk Region, which is located in Northern European Russia. In 2015, the Shenkursk District had a population of 13,530, which dropped to 12,610 in $2018[27,28]$. The district is largely rural, with $62 \%$ of the population living in the countryside. Due to the Northern location of the district $\left(62^{\circ} 06^{\prime} \mathrm{N}, 42^{\circ} 54^{\prime} \mathrm{E}\right)$, temperatures below zero prevail from October to April [29].

The local economy is based mainly on forestry, woodworking, and agriculture. The street and walkway infrastructure is poorly developed; walkways are largely made of wood or concrete, or have a gravel surface, and street lights are placed only on major streets. Healthcare in the district is provided by one central district hospital (CDH) that has in-patient facilities and out-patient polyclinics and by rural healthcare facilities, including two out-patient clinics and 23 local units served by nurses. Approximately $80 \%$ of injuries in the Shenkursk District are treated at the CDH [30].

\subsection{Study Population and Injury Data}

Data on non-fatal AOFIs were obtained from the Shenkursk Injury Registry (SHIR) for the period from 1 January 2015 through 30 June 2018 [30,31]. The SHIR gathers information on all injuries (ICD-10 codes from S00 to T78) treated at the Shenkursk CDH. Data are collected through the use of a universal injury registration form (IRF) - a two-page sheet with several sections for recording information about injured patients, including socio-demographic characteristics (sex, date of birth, address, place of work or study), information about time and place of injury, alcohol consumption in the $24 \mathrm{~h}$ prior to injury, use of protective equipment, and special sections for descriptions of road traffic and sports injuries. The IRF also has a mandatory section in which a free-text description of how 
the injury occurred is included. This section includes three supportive questions aimed to structure the description of injury circumstances: "What were you doing?", "What went wrong?", and "How were you injured?". The free-text replies to these questions are transformed into categorical variables in the SHIR by trained and calibrated registrars, who define the three corresponding mechanisms (i.e., the mechanism of preceding activity, the accident mechanism, and the injury mechanism) using the appropriate coding lists.

Injured patients who are treated in the Shenkursk CDH are asked to fill out the IRF at their first outpatient or ambulance visit, or within a few days of hospitalization. If necessary, relatives, a nurse, or a physician can help the injured patient complete the IRF. If the IRF is not filled out due to a patient's severe condition or other reasons, injury registrars complete the form retrospectively (about $40 \%$ of cases). For that purpose, they use data from routine medical records (ambulance journal, outpatient medical card, case history) and information obtained from the attending physician. Attending physicians have to fill out the concluding part of the IRF, which includes the diagnosis with the corresponding ICD-10 code, injury severity according to the Abbreviated Injury Scale (AIS), and a record on whether the patient was hospitalized. A more detailed description of the SHIR and the IRF can be found elsewhere [30,31].

The SHIR variables used in this study were sex, age, injury localization by ICD-10 code, injury severity according to the AIS, hospitalization (yes, no), day (weekday or weekend) and time of the injury, the mechanism of preceding activity, the accident mechanism, and the injury mechanism.

\subsection{Weather Conditions}

Data on weather conditions for the period from 1 January 2015 through 30 June 2018 in the Shenkursk District were obtained from the website of the Raspisaniye Pogodi Ltd., St. Petersburg, Russia [32], which includes daily archive records from the Shenkursk weather station. The weather station measures air temperature $\left({ }^{\circ} \mathrm{C}\right)$, atmospheric pressure $(\mathrm{hPa})$, wind speed $(\mathrm{m} / \mathrm{s})$, and relative humidity (\%) eight times a day (every $3 \mathrm{~h}$ ); amount of precipitation $(\mathrm{mm})$ per $12 \mathrm{~h}$ is measured twice a day (at 6:00 a.m. and 6:00 p.m.; only measurements taken at 6:00 p.m. were used); and ground surface conditions are measured once a day at 6:00 a.m. (dry or moist for the warm season; no snow, covered with loose dry snow, and covered with compact or wet snow for the cold season). All of these variables were used in this study.

Assuming that associations between weather conditions and daily numbers of AOFIs can be non-linear, mean daily air temperature $\left({ }^{\circ} \mathrm{C}\right)$, mean daily atmospheric pressure $(\mathrm{hPa})$, mean daily wind speed (m/s), and mean daily relative humidity (\%) were categorized as "low", "medium", or "high" for each season, using the 1st and the 2nd tertiles as cut-off values. The same categorization for each season was used for the amount of precipitation $(\mathrm{mm})$; however, in the warm season, all values below the first tertile were equal to zero. For this reason, the three categories of daily amount of precipitation were labeled as "none", "low", and "medium/high".

\subsection{Data Analysis}

The associations between the weather conditions and the AOFIs were investigated separately for the cold season (15 October to 14 April) and the warm season (15 April to 14 October). Categorical characteristics of AOFIs are presented as absolute numbers and percentages. Chi-squared tests were used to compare the characteristics of AOFIs in the two seasons.

We applied negative binomial regression for the cold season and zero-inflated Poisson regression for the warm season to model daily numbers of AOFIs, with categorized weather characteristics entered as regressors [33]. The "countfit" function in Stata was used to select the most appropriate models, based on the Akaike Information Criterion and Bayesian Information Criterion [33]. Robust standard errors were calculated for all estimates to adjust for heterogeneity in the models. All two-way interactions between weather condition variables were investigated by entering the corresponding interaction terms into multivariable models. Average percent changes (APCs) with $95 \%$ confidence 
intervals (CIs) were estimated by regression models to assess changes in daily numbers of AOFIs per one-unit change in each independent weather condition variable.

Heat-maps of the daily incidence of AOFIs per 100,000 of the total population of Shenkursk District were built for each season and for combinations of the significant weather predictors. All statistical analyses were performed using STATA v. 16.1 (StataCorp LLC, 2020, College Station, TX, USA ).

\section{Results}

The present study included 651 days of the cold season and 626 days of the warm season. The median air temperature in the cold season was $-3.1{ }^{\circ} \mathrm{C}$, and in the warm season, it was $12.2{ }^{\circ} \mathrm{C}$ (Table 1). In the warm season, $2.2 \%$ of days had a mean daily air temperature $<0{ }^{\circ} \mathrm{C}$, while this was the case for $73.1 \%$ of days in the cold season. The median atmospheric pressure and amount of precipitation were similar in the two seasons, whereas the median relative humidity was higher in the cold season. Besides, in the cold season, the ground surface was covered with loose dry snow in $64.8 \%$ of the total days; it was covered with compact or wet snow in $25.0 \%$ of the days (Table 1 ).

Table 1. Weather conditions in the Shenkursk District by season, 1 January 2015-30 June 2018.

\begin{tabular}{|c|c|c|}
\hline Weather Conditions & $\begin{array}{l}\text { Cold Season } \\
15 \text { October-14 April } \\
\text { (651 Days) }\end{array}$ & $\begin{array}{c}\text { Warm Season } \\
15 \text { April-14 October } \\
\text { (626 Days) }\end{array}$ \\
\hline \multicolumn{3}{|c|}{ Mean daily air temperature, ${ }^{\circ} \mathrm{C}$} \\
\hline Minimum & -39.9 & -9.9 \\
\hline 1st tertile & -7.0 & 9.0 \\
\hline Median & -3.1 & 12.2 \\
\hline 2th tertile & -0.6 & 15.2 \\
\hline Maximum & 12.8 & 31.3 \\
\hline \multicolumn{3}{|c|}{ Mean daily atmospheric pressure, $\mathrm{hPa}$} \\
\hline Minimum & 964.2 & 971.0 \\
\hline 1st tertile & 1002.2 & 1003.6 \\
\hline Median & 1007.5 & 1007.6 \\
\hline 2 th tertile & 1013.4 & 1011.1 \\
\hline Maximum & 1048.3 & 1038.5 \\
\hline \multicolumn{3}{|l|}{ Mean daily wind speed, $\mathrm{m} / \mathrm{s}$} \\
\hline Minimum & 0.0 & 0.0 \\
\hline 1st tertile & 2.4 & 2.1 \\
\hline Median & 2.9 & 2.5 \\
\hline 2 th tertile & 3.5 & 2.8 \\
\hline Maximum & 10.0 & 9.0 \\
\hline \multicolumn{3}{|c|}{ Mean daily relative humidity, $\%$} \\
\hline Minimum & 20.0 & 12.0 \\
\hline 1st tertile & 82.2 & 65.2 \\
\hline Median & 86.0 & 72.0 \\
\hline 2th tertile & 88.4 & 79.1 \\
\hline Maximum & 99.0 & 100.0 \\
\hline \multicolumn{3}{|c|}{ Amount of precipitation per $12 \mathrm{~h}$ measured at 6:00 p.m., mm } \\
\hline Minimum & 0.0 & 0.0 \\
\hline 1st tertile & 0.1 & 0.0 \\
\hline Median & 0.1 & 0.1 \\
\hline 2th tertile & 0.4 & 0.3 \\
\hline Maximum & 10.0 & 14.0 \\
\hline \multicolumn{3}{|c|}{ Ground surface condition measured at 6:00 a.m., $\%$ of days } \\
\hline Dry soil & 0.0 & 53.8 \\
\hline Moist soil & 10.1 & 41.1 \\
\hline Loose dry snow & 64.8 & 1.9 \\
\hline Compact or wet snow & 25.0 & 3.2 \\
\hline
\end{tabular}


There were 1125 non-fatal AOFIs recorded in the SHIR in the study period (Table 2$)$. This constituted $21 \%$ of all injuries registered in the SHIR for that period and $73 \%$ of all accidental fall injuries (indoor and outdoor). The mean daily number of AOFIs in the study period was 0.88 , and this number was 1.7 times higher in the cold season compared to the warm season (1.10 vs. 0.65 , respectively). Correspondingly, the mean daily incidence of AOFIs in the study period was 6.7 per 100,000 population, 8.4 in the cold season and 5.0 in the warm season. The median daily incidence of AOFIs in the study period was 7.7 per 100,000 population. The distribution of AOFIs by sex, injury severity, proportion of hospitalizations, proportion of AOFIs that occurred on weekends, and by time of day was not significantly different between the two seasons (Table 2). The proportion of AOFIs among children was higher in the warm season $(p<0.001)$, and the proportion of trunk injuries was higher in the cold season $(p=0.023)$. Notably, $12.9 \%$ of adults with AOFIs in the cold period and $11.7 \%$ in the warm period reported drinking alcohol in the preceding $24 \mathrm{~h}(p=0.774)$.

Table 2. Socio-demographic, medical, and temporal characteristics of medically-treated, non-fatal accidental outdoor fall injuries in the Shenkursk District by season, 1 January 2015-30 June 2018.

\begin{tabular}{|c|c|c|c|}
\hline Characteristics & $\begin{array}{c}\text { Cold Season } \\
15 \text { October-14 April, \% } \\
(N=717)\end{array}$ & $\begin{array}{c}\text { Warm Season } \\
15 \text { April-14 October, \% } \\
(N=408)\end{array}$ & $p$ \\
\hline Sex, male & 48.1 & 51.7 & 0.246 \\
\hline Age group, years & & & $<0.001$ \\
\hline $0-6$ & 1.3 & 7.4 & \\
\hline $7-17$ & 17.6 & 22.5 & \\
\hline $18-59$ & 54.4 & 45.3 & \\
\hline $60+$ & 26.8 & 24.8 & \\
\hline Injury localization, ICD-10 & & & 0.023 \\
\hline S00-09: Head & 9.6 & 10.3 & \\
\hline S10-39: Trunk & 21.1 & 14.2 & \\
\hline S40-69: Upper extremity & 40.7 & 43.1 & \\
\hline S70-99: Lower extremity & 28.2 & 30.9 & \\
\hline Other & 0.4 & 1.5 & \\
\hline Injury severity, AIS & & & 0.816 \\
\hline 1 Minor & 58.0 & 56.1 & \\
\hline 2 Moderate & 31.4 & 33.1 & \\
\hline 3 Severe, but not life-threatening & 10.6 & 10.8 & \\
\hline Hospitalization, yes & 10.7 & 13.2 & 0.210 \\
\hline Injury occurred on weekend * & 29.8 & 29.4 & 0.878 \\
\hline Time of injury, hours & & & 0.200 \\
\hline 00:00-05:59 & 4.2 & 3.7 & \\
\hline 06:00-11:59 & 20.8 & 18.5 & \\
\hline $12: 00-17: 59$ & 41.8 & 38.2 & \\
\hline 18:00-23:59 & 26.4 & 29.6 & \\
\hline Not indicated & 6.9 & 10.1 & \\
\hline
\end{tabular}

* Saturday and Sunday. ICD-10: International Classification of Diseases, Revision 10; AIS: Abbreviated Injury Scale.

The distribution of AOFIs by the mechanism of the preceding activity, accident mechanism, and injury mechanism was significantly different in the two seasons $(p<0.001)$ (Table 3). Walking was a more frequent mechanism of preceding activity in the cold season compared to the warm season $(64.7 \%$ vs. $45.1 \%)$. Such mechanisms of preceding activity as standing and sitting, climbing up/down, and running were more frequent in the warm season. AOFI cases in the warm season who had climbing up/down and running recorded as the mechanism of preceding activity were largely children (13.9\% and $27.0 \%$ respectively). The most common accident mechanism in the cold season was slipping 
$(82.7 \%)$, while stepping wrong or stumbling over something was the most typical (48.8\%) accident mechanism in the warm season. A fall on the same level was the dominating injury mechanism in both seasons, but the proportion of injuries due to falls from a height was relatively higher in the warm season $(15.4 \%$ vs. $3.5 \%)$ (Table 3$)$.

Table 3. Mechanisms of medically-treated, non-fatal accidental outdoor fall injuries in Shenkursk District by season, 1 January 2015-30 June 2018.

\begin{tabular}{|c|c|c|c|}
\hline Mechanisms & $\begin{array}{c}\text { Cold Season } \\
15 \text { October-14 April, \% } \\
(N=717)\end{array}$ & $\begin{array}{c}\text { Warm Season } \\
15 \text { April-14 October, \% } \\
(N=408)\end{array}$ & $p$ \\
\hline Mechanism of preceding activity & & & $<0.001$ \\
\hline Walking & 64.7 & 45.1 & \\
\hline Carrying something & 10.6 & 4.9 & \\
\hline Physical exercising & 8.1 & 8.8 & \\
\hline Going on a stairs & 7.4 & 5.6 & \\
\hline Working in a garden & 5.2 & 9.6 & \\
\hline Standing and sitting & 2.6 & 11.3 & \\
\hline Climbing up/down & 0.8 & 5.9 & \\
\hline Running & 0.6 & 8.8 & \\
\hline Accident mechanism & & & $<0.001$ \\
\hline Slipping & 82.7 & 27 & \\
\hline Stepping wrong or stumbling over something & 7.9 & 48.8 & \\
\hline Loss of balance and faintness & 5.7 & 14.7 & \\
\hline Other & 3.6 & 9.6 & \\
\hline Injury mechanism & & & $<0.001$ \\
\hline Fall on the same level & 83.7 & 71.8 & \\
\hline Fall on a stairs & 12.8 & 12.7 & \\
\hline Fall from a height & 3.5 & 15.4 & \\
\hline
\end{tabular}

The results of univariate regression analyses showed that, in the cold season, daily numbers of AOFIs were associated with air temperature, atmospheric pressure, amount of precipitation, and a ground surface covered by snow (Table 4). Additional regression that used a binary weekend variable (Saturday and Sunday coded as "yes" and other weekdays as "no"; a proxy measure for alcohol consumption) as a regressor was not significant $(p=0.471)$. Multivariable regression for the cold season that included all weather condition variables showed that the highest daily numbers of AOFIs occurred on days when the mean daily air temperature was medium $\left(-7.0^{\circ} \mathrm{C}\right.$ to $\left.-0.7^{\circ} \mathrm{C}\right)$. Daily numbers of AOFIs were significantly lower on days with high mean daily air temperature $\left(\geq-0.6^{\circ} \mathrm{C}\right.$; $\mathrm{APC}=-29.0 \%$; $p=0.039)$. They were also lower on days with low mean daily air temperature $\left(\leq-7.1^{\circ} \mathrm{C} ; \mathrm{APC}=-20.7 \%\right.$; $p=0.058)$, but the association did not reach the level of significance. Daily numbers of AOFIs were also significantly higher on days with medium/high precipitation $(\geq 0.4 \mathrm{~mm} ; \mathrm{APC}=24.3 \% ; p=0.015)$ relative to days with low precipitation $(0.1$ to $0.3 \mathrm{~mm})$, and on days when the ground surface was covered by compact or wet snow compared to days when the ground surface had no snow (APC $=57.9 \%$; $p=0.003$ ) (Table 4). No interactions between independent variables in the cold season were observed. 
Table 4. Associations of weather condition variables with daily numbers of medically-treated, non-fatal outdoor accidental fall injuries in the Shenkursk District in the cold season (15 October-14 April).

\begin{tabular}{|c|c|c|c|c|c|c|}
\hline \multirow{2}{*}{ Weather Conditions } & \multirow{2}{*}{$\begin{array}{c}\mathbf{N} \\
\text { Days }\end{array}$} & \multirow{2}{*}{$\begin{array}{c}\mathbf{N} \\
\text { Cases }\end{array}$} & \multicolumn{2}{|c|}{ Simple Negative Binomial Regression } & \multicolumn{2}{|c|}{ Multivariable Negative Binomial Regression * } \\
\hline & & & APC, $\%(95 \%$ CI $)$ & $p$ & APC, $\%(95 \%$ CI $)$ & $p$ \\
\hline \multicolumn{7}{|c|}{ Mean daily air temperature, ${ }^{\circ} \mathrm{C}$} \\
\hline Low $(\leq-7.1)$ & 217 & 212 & $-26.7(-46.9,-6.6)$ & 0.009 & $-20.7(-42.0,0.7)$ & 0.058 \\
\hline Med $(-7.0$ to -0.7$)$ & 217 & 277 & Ref. & & Ref. & \\
\hline $\operatorname{High}(\geq-0.6)$ & 217 & 228 & $-20.4(-41.6,0.8)$ & 0.072 & $-29.0(-56.6,-1.4)$ & 0.039 \\
\hline \multicolumn{7}{|c|}{ Mean daily atmospheric pressure, $\mathrm{hPa}$} \\
\hline Low $(\leq 1002.1)$ & 217 & 259 & $1.6(-19.0,22.1)$ & 0.882 & $-1.4(-21.4,18.5)$ & 0.888 \\
\hline Med (1002.2 to 1013.2) & 217 & 255 & Ref. & & Ref. & \\
\hline High $(\geq 1013.3)$ & 217 & 203 & $-22.8(-43.4,-2.2)$ & 0.03 & $-15.8(-36.6,5.0)$ & 0.137 \\
\hline \multicolumn{7}{|c|}{ Mean daily wind speed, $\mathrm{m} / \mathrm{s}$} \\
\hline Low $(\leq 2.3)$ & 233 & 234 & $-13.0(-34.5,8.4)$ & 0.233 & $-5.1(-26.3,16.1)$ & 0.638 \\
\hline Med (2.4 to 3.4$)$ & 208 & 238 & Ref. & & Ref. & \\
\hline $\operatorname{High}(\geq 3.5)$ & 210 & 245 & $1.9(-19.1,23.0)$ & 0.857 & $-1.2(-22.5,20.2)$ & 0.913 \\
\hline \multicolumn{7}{|c|}{ Mean daily relative humidity $\%$} \\
\hline Low $(\leq 82.1)$ & 219 & 233 & $-5.6(-26.2,15.0)$ & 0.596 & $-2.7(-24.7,19.2)$ & 0.808 \\
\hline Med (82.2 to 88.3$)$ & 216 & 243 & Ref. & & Ref. & \\
\hline High $(\geq 88.4)$ & 216 & 241 & $-0.8(-21.6,19.9)$ & 0.938 & $-11.0(-31.6,9.6)$ & 0.293 \\
\hline \multicolumn{7}{|c|}{ Amount of precipitation per $12 \mathrm{~h}$ measured at 6:00 p.m., mm } \\
\hline No $(0.0)$ & 176 & 186 & $10.0(-11.3,31.3)$ & 0.359 & $6.2(-15.5,28.0)$ & 0.574 \\
\hline Low $(0.1$ to 0.3$)$ & 252 & 241 & Ref. & & Ref. & \\
\hline Med/High $(\geq 0.4)$ & 223 & 290 & $30.7(10.9,50.6)$ & 0.002 & $24.3(4.7,43.8)$ & 0.015 \\
\hline \multicolumn{7}{|c|}{ Ground surface condition measured at 6.00 a.m. } \\
\hline No snow & 66 & 47 & Ref. & & Ref. & \\
\hline Loose dry snow & 422 & 453 & $41.0(6.2,75.8)$ & 0.021 & $26.7(-14.4,67.8)$ & 0.203 \\
\hline Compact/wet snow & 163 & 217 & $62.6(25.2,100.0)$ & 0.001 & $57.9(20.1,95.6)$ & 0.003 \\
\hline
\end{tabular}

${ }^{*}$ Constant $=-6.1(95 \%$ CI: $-49.9,37.6), p=0.783 \mathrm{~N}$ : number; APC: average percent change; CI: confidence interval. 
In the warm season, the results of univariate regression analyses showed that daily numbers of AOFIs were associated with air temperature and atmospheric pressure (Table 5). The model that included the binary weekend variable rendered insignificant results $(p=0.848)$, as was the case in the cold season. Multivariable regression for the warm season that included all weather condition variables showed that daily numbers of AOFIs were significantly lower on days with high mean daily air temperature $\left(\geq 15.2^{\circ} \mathrm{C}\right.$; APC $\left.=-15.3 \% ; p=0.034\right)$ compared to days with medium air mean daily temperature $\left(9.0^{\circ} \mathrm{C}\right.$ to $\left.15.1^{\circ} \mathrm{C}\right)$. Additionally, the daily numbers of AOFIs were lower on days with low mean daily atmospheric pressure $(\leq 1003.5 \mathrm{hPa} ; \mathrm{APC}=-15.7 \% ; p=0.015)$ relative to days with medium mean daily atmospheric pressure (1003.6 to $1010.9 \mathrm{hPa}$ ). The testing of two-way interactions between weather condition variables in the warm season detected modifications of the association between mean daily relative humidity and AOFIs by the daily amount of precipitation $(p=0.048)$ and by the ground surface condition $(p=0.045)$. The two corresponding interaction terms were entered into the final multivariable regression model and both sustained statistical significance. Additional stratified analysis of the associations between the mean daily relative humidity and daily AOFI numbers by the daily amount of precipitation and ground surface conditions (not presented) showed that low relative humidity had associations with smaller AOFI numbers (analysis of 56 observations; $p<0.001$ ) only when the precipitation was low and soil was dry, while high relative humidity had associations with larger AOFI numbers when there was no precipitation but the soil was moist (114 observations; $p=0.018$.

According to the heat-map of AOFI incidence, which included only the weather condition variables that reached statistical significance in multivariable regression models (Figure 1), the highest incidence of AOFIs (20.2 per 100,000 population) was observed during the cold season on days when the ground surface was covered by compact or wet snow, there was a medium mean daily air temperature $\left(-7.0^{\circ} \mathrm{C}\right.$ to $\left.-0.7^{\circ} \mathrm{C}\right)$, and there was medium/high precipitation $(\geq 0.4 \mathrm{~mm})$. The heat-map shows that the AOFI incidence in the warm season was substantially lower than that in the cold season. The relatively high AOFI incidence (7.0 per 100,000 population) in the warm season occurred on days with medium mean daily air temperature $\left(9.0^{\circ} \mathrm{C}\right.$ to $\left.15.1^{\circ} \mathrm{C}\right)$ and medium atmospheric pressure (1003.6 to $1010.9 \mathrm{hPa}$ ). 
Table 5. Associations of weather condition variables with daily numbers of medically-treated, non-fatal accidental outdoor fall injuries in the Shenkursk District in the warm season (15 April-14 October).

\begin{tabular}{|c|c|c|c|c|c|c|}
\hline \multirow{2}{*}{ Weather Conditions } & \multirow{2}{*}{$\begin{array}{c}\mathbf{N} \\
\text { Days }\end{array}$} & \multirow{2}{*}{$\begin{array}{c}\mathbf{N} \\
\text { Cases }\end{array}$} & \multicolumn{2}{|c|}{ Simple Zero-Inflated Poisson Regression } & \multicolumn{2}{|c|}{ Multivariable Zero-Inflated Poisson Regression * } \\
\hline & & & $\mathrm{APC} \%(95 \% \mathrm{CI})$ & $p$ & APC, $\%(95 \% \mathrm{CI})$ & $p$ \\
\hline \multicolumn{7}{|l|}{ Mean daily air temperature, ${ }^{\circ} \mathrm{C}$} \\
\hline Low $(\leq 8.9)$ & 210 & 123 & $-3.9(-16.5,8.7)$ & 0.544 & $-0.8(-14.4,12.8)$ & 0.906 \\
\hline Med (9.0 to 15.1$)$ & 208 & 161 & Ref. & & Ref. & \\
\hline High $(\geq 15.2)$ & 208 & 124 & $-14.2(-27.1,-1.3)$ & 0.030 & $-15.3(-29.5,-1.1)$ & 0.034 \\
\hline \multicolumn{7}{|l|}{ Mean daily atmospheric pressure, $\mathrm{hPa}$} \\
\hline Low $(\leq 1003.5)$ & 209 & 136 & $-13.8(-26.6,0.1)$ & 0.035 & $-15.7(-28.4,-3.1)$ & 0.015 \\
\hline Med (1003.6 to 1010.9) & 210 & 144 & Ref. & & Ref. & \\
\hline High $(\geq 1011)$ & 207 & 128 & $-5.3(-18.3,7.8)$ & 0.429 & $-6.0(-19.6,7.5)$ & 0.382 \\
\hline \multicolumn{7}{|l|}{ Mean daily wind speed, $\mathrm{m} / \mathrm{s}$} \\
\hline Low $(\leq 2.0)$ & 218 & 141 & $1.9(-11.0,14.7)$ & 0.779 & $0.6(-13.3,14.5)$ & 0.935 \\
\hline Med (2.1 to 2.7) & 202 & 137 & Ref. & & Ref. & \\
\hline High $(\geq 2.8)$ & 206 & 130 & $0.0(-12.9,13.0)$ & 0.994 & $-1.4(-14.5,11.7)$ & 0.834 \\
\hline \multicolumn{7}{|l|}{ Mean daily relative humidity, $\%$} \\
\hline Low $(\leq 65.1)$ & 211 & 136 & $2.9(-10.5,16.3)$ & 0.676 & $-4.6(-35.3,26.0)$ & 0.766 \\
\hline Med (65.2 to 79.0$)$ & 208 & 128 & Ref. & & Ref. & \\
\hline High $(\geq 79.1)$ & 207 & 144 & $3.4(-9.6,16.4)$ & 0.604 & $-12.6(-68.9,43.7)$ & 0.661 \\
\hline \multicolumn{7}{|l|}{ Amount of precipitation per $12 \mathrm{~h}$ measured at 6:00 p.m., mm } \\
\hline No $(0.0)$ & 294 & 195 & $4.6(-10.0,19.1)$ & 0.535 & $-6.8(-24.9,11.4)$ & 0.464 \\
\hline Low (0.1 to 0.2 ) & 129 & 80 & Ref. & & Ref. & \\
\hline Med/High $(\geq 0.3)$ & 203 & 133 & $2.5(-12.9,18.0)$ & 0.747 & $-17.2(-45.0,10.7)$ & 0.227 \\
\hline \multicolumn{7}{|l|}{ Ground surface condition measured at 6.00 a.m. } \\
\hline Dry & 337 & 233 & Ref. & & Ref. & \\
\hline Moist & 257 & 153 & $-4.9(-16.0,6.2)$ & 0.389 & $4.7(-11.1,20.5)$ & 0.561 \\
\hline Loose dry snow & 12 & 8 & $10.0(-17.8,37.9)$ & 0.480 & $29.8(-3.3,62.9)$ & 0.077 \\
\hline Compact/wet snow & 20 & 14 & $-3.3(-26.2,19.6)$ & 0.777 & $24.5(-3.6,52.7)$ & 0.088 \\
\hline Mean daily relative humidity ${ }^{*}$ Amount of precipitation per $12 \mathrm{~h}$ & & & & & $9.1(-0.2,18.1)$ & 0.045 \\
\hline Mean relative humidity * Ground surface condition & & & & & $-10.2(-19.9,-0.5)$ & 0.039 \\
\hline
\end{tabular}

${ }^{*}$ constant $=54.0(95 \%$ CI: 28.7, 79.2), $p<0.001 . \mathrm{N}$ : number; APC: average percent change; CI: confidence interval. 
Compact/wet snow, 15 October-14 April

\begin{tabular}{|c|c|c|c|c|}
\hline & & \multicolumn{3}{|c|}{$\begin{array}{l}\text { Amount of precipitation per } 12 \mathrm{~h} \\
\text { measured at } 6.00 \text { p.m., mm }\end{array}$} \\
\hline & & No & $\begin{array}{l}\text { Low } \\
0.1 \text { to } 0.3\end{array}$ & $\begin{array}{c}\text { Med/high } \\
\quad \geq 0.4\end{array}$ \\
\hline \multirow{3}{*}{ 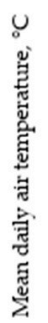 } & $\begin{array}{l}\text { Low } \\
\leq-7.1\end{array}$ & n.a. ${ }^{*}$ & n.a. & n.a. \\
\hline & $\begin{array}{c}\text { Med } \\
-7.0 \text { to } \\
-0.7\end{array}$ & 13.8 & 9.2 & 20.2 \\
\hline & $\begin{array}{l}\text { High } \\
\geq-0.6\end{array}$ & 9.2 & 7.5 & 10.3 \\
\hline
\end{tabular}

No snow, 15 October-14 April

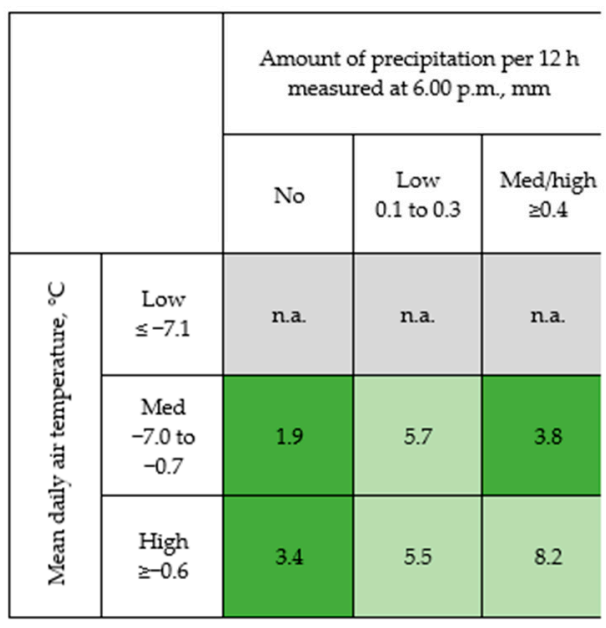

Loose dry snow, 15 October-14 April

\begin{tabular}{|c|c|c|c|c|}
\hline & & \multicolumn{3}{|c|}{$\begin{array}{l}\text { Amount of precipitation per } 12 \mathrm{~h} \\
\text { measured at } 6.00 \text { p.m., mm }\end{array}$} \\
\hline & & No & $\begin{array}{l}\text { Low } \\
0.1 \text { to } 0.3\end{array}$ & $\begin{array}{l}\text { Med/high } \\
\quad \geq 0.4\end{array}$ \\
\hline \multirow{3}{*}{ 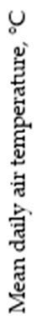 } & $\begin{array}{l}\text { Low } \\
\leq-7.1\end{array}$ & 6.9 & 7.1 & 8.1 \\
\hline & $\begin{array}{c}\text { Med } \\
-7.0 \text { to } \\
-0.7\end{array}$ & 7.9 & 8.0 & 11.1 \\
\hline & $\begin{array}{l}\text { High } \\
\geq-0.6\end{array}$ & 9.8 & 7.7 & 6.9 \\
\hline
\end{tabular}

15 April-14 October

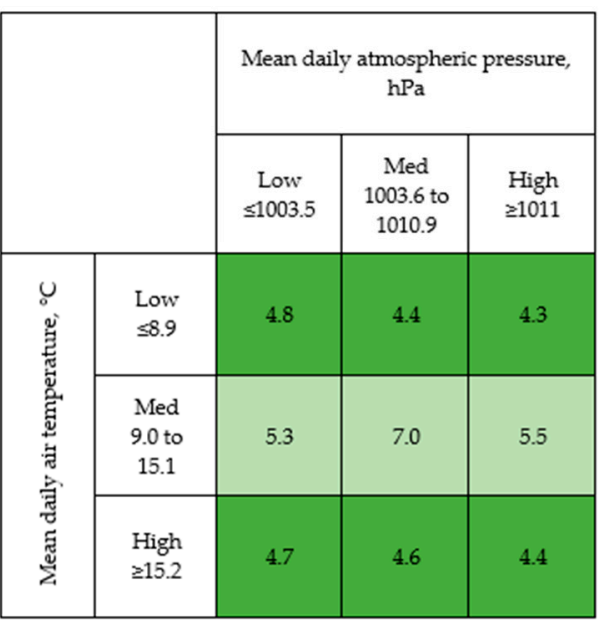

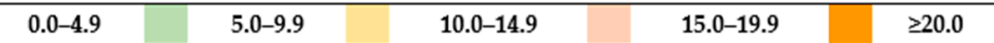

Figure 1. Heat-map of the mean daily incidence (per 100,000 population) of medically-treated, non-fatal accidental outdoor fall injuries in the cold season (15 October-14 April) according to ground-surface conditions, mean daily air temperature, and amount of precipitation per $12 \mathrm{~h}$ measured at 6.00 p.m. and in the warm season (15 April-14 October) according to mean daily air temperature and mean daily atmospheric pressure; Shenkursk District, 1 January 2015-30 June 2018. * Mean is not calculated due to lacking observations. N.a.: not applicable.

\section{Discussion}

To the best of our knowledge, this is the first Russian registry-based study investigating the associations between weather conditions and medically-treated, non-fatal AOFIs in Northwestern Russia. The results demonstrate that the mean daily number of AOFIs in the cold season was $70 \%$ higher than that in the warm season. In the cold season, daily numbers of AOFIs were independently associated with air temperature, amount of precipitation, and ground surface conditions. Days that had a combination of air temperature between $-7.0^{\circ} \mathrm{C}$ and $-0.7^{\circ} \mathrm{C}, 2$, an amount of precipitation above $0.4 \mathrm{~mm}$, and a ground surface covered with compact or wet snow were described as the most "risky days" with respect to AOFIs. In the warm season, daily numbers of AOFIs were independently associated with air temperature and atmospheric pressure. The highest AOFI incidence was observed on days with an air temperature between $9.0^{\circ} \mathrm{C}$ and $15.1^{\circ} \mathrm{C}$, and an atmospheric pressure between 
1003.6 to $1010.9 \mathrm{hPa}$. However, the highest incidence of AOFIs observed in the warm season was substantially lower than that observed in the cold season.

Adults of working age made up the largest proportion of cases of medically-treated non-fatal AOFIs in the Shenkursk District. However, the proportion of AOFIs in children was greater in the warm season compared to the cold season. Similarly, a study from the UK found that the number of pediatric admissions with injuries and fractures increased in the summer period [34]. This can be explained by the fact that, in the warm season, children have more spare time. They are more often outside, and thus are more likely to fall outdoors.

The seasonal variation in AOFIs that we observed in the Shenkursk District is in accordance with studies carried out both in the Nordic countries and in countries with a warm climate. In Norway, Finland, Sweden, and Canada, the distribution of fall-related injuries and fractures varied by season and had a higher occurrence during the winter months $[2,3,17,18,35,36]$. For example, in three urban areas in Norway (Stavanger, Trondheim, and Harstad) the incidence rate of arm fractures among older adults was $69 \%$ higher during the colder season compared with the warmer season [17]. A study conducted in northern Sweden showed that most of the fall injuries (81\%) in public outdoor environments among pedestrians 65 years and older occurred during the winter period (November to April) [2]. Even studies in Hong Kong and Taiwan demonstrated an increasing likelihood of outdoor falls in the winter months, even though the winter temperatures in these countries are well above $0{ }^{\circ} \mathrm{C}[19,22]$. In the Nordic countries, falls occur more often in the cold season because of hazardous winter-related environmental conditions and biological factors, such as a general weakening of the body due to non-optimal vitamin $\mathrm{D}$ status [17,36-39]. However, the evidence about the association between vitamin D and falls or fractures is inconclusive [40]. A meta-analysis by Bolland et al. [41] has not shown a preventive effect of vitamin D on fractures or falls while Bischoff-Ferrari et al. [42] has demonstrated a reduction in the total number of fractures and falls by $14 \%$ and $12 \%$, respectively, due to consumption of $800-1000$ IU vitamin D daily.

Air temperature is a well-known meteorological risk factor for outdoor falls. Many studies have shown an association between below-zero temperatures and a higher incidence of fall-related fractures $[2,18,25,35]$. In our study, the highest risks of AOFIs were observed on days with an air temperature between $-7.0^{\circ} \mathrm{C}$ and $-0.7^{\circ} \mathrm{C}$. These may be considered relatively comfortable winter temperatures in which people are more likely to participate in outdoor activities compared to colder days, as well as compared to days when temperatures rise above zero and it becomes wet. In addition, De Koning et al. [43] described that the minimum friction coefficient occurs when the ice surface temperature is between $-6{ }^{\circ} \mathrm{C}$ and $-9{ }^{\circ} \mathrm{C}$, which is that the worst outdoor temperature interval for walking outside, as that is when slip and fall accidents are most likely [44]. Contrary to that, a study from Finland described that the incidence of outdoor falls among elderly people was 3.4 times higher when the temperature was below $-20^{\circ} \mathrm{C}$ than when it was between $-10^{\circ} \mathrm{C}$ and $0{ }^{\circ} \mathrm{C}$ [35]. That means that associations between AOFIs and weather conditions can vary in different settings, even if they have a similar climate. This may be due to different outdoor environments, or varying traditions of outdoor activities in the winter time. This also outlines the importance of using local injury data when planning preventive activities [45].

Ice and snow are well-known causes of fall-related injuries. In the present study, a ground surface covered by loose dry snow or compact/wet snow increased daily numbers of AOFIs in the cold season by $41 \%$ and $63 \%$, respectively, compared with days when the ground surface had no snow. A study performed in Canada found a significant, positive correlation $(\mathrm{r}=0.33-0.60 ; p<0.001)$ between snow depth and the number of snowy days and hip fractures for all age groups and sexes [18]. The city of Philadelphia, Pennsylvania in the USA also recorded increases in fall-related patient visits after snow and ice storms [46].

In the cold season, walking was the most common mechanism of activity preceding an AOFI $(65 \%)$ in the Shenkursk District, while slipping was the most common accident mechanism (83\%). Similar results were obtained in Umeå, Sweden, where $85 \%$ of persons injured due to slipping on ice or 
snow and falling outdoors were walking before the accident [13]. The results from a Finnish study showed that the number of fractures on slippery winter days and on the days immediately following was 2.5 times higher compared to non-wintertime (April 16 to October 15) [3]. During a snow crisis in Iran, slipping was the most common injury mechanism, and the frequency of injuries on icy days was $32.4 \%$ higher than that on snowy days [21].

We found that "the riskiest days" in terms of AOFIs in the cold season were the days with a combination of medium air temperature, medium/high precipitation, and a ground surface covered with compact or wet snow. The importance of describing these "high-risk combinations" of weather characteristics has been outlined in other studies. For example, Lépy et al. [24] described six winter scenarios with respect to slippery conditions and identified the most common scenario of slipperiness to be a combination of relative humidity above $95 \%$, surface temperature below $0{ }^{\circ} \mathrm{C}$, and a surface temperature lower than the dewpoint. This type of slipperiness accounted for $50 \%$ of injuries. Morency et al. also showed that a combination of below-zero temperatures, snowfalls, and freezing rain leads to excess cases of outdoor falls [25].

Our study demonstrated that, in the warm season, a higher frequency of AOFIs was observed on days with medium air temperature and medium atmospheric pressure. Previous studies of falls have scarcely addressed the role of atmospheric pressure, and only a few reported that atmospheric pressure has an effect on the incidence of hip fractures and trauma admissions $[19,20]$. However, it is known that low atmospheric pressure can cause headaches, a feeling of dizziness and decreases in blood pressure among weather-sensitive people [47-49]. The association between dizziness and falls among middle-aged adults was found by Peeters et al. [50] during the analysis of data from population-based cohort studies in Australia and the UK. One possible explanation for the phenomenon observed in our study is that days with average air temperatures and atmospheric pressures may be the most comfortable for outdoor activities, and thus the higher incidence could be due to higher outdoor exposure.

As the incidence of AOFIs in the Shenkursk District is the highest in the cold season and slipping is the most common accident mechanism, our study suggests that efforts to prevent AOFIs should primarily target the problem of icy ground surfaces. The common approaches are spreading anti-slip materials (sand, salt, gravel) on walkways and using slip-resistant footwear. The latter may be a feasible solution for a rural setting. Protective effects of gait-stabilizing and anti-slip devices in the winter season were demonstrated in earlier studies [51,52]. In addition to these standard approaches, it may be helpful to inform people about the increased risks when such risks are expected. For that purpose, our descriptions of "high-risk days" can supplement regular weather forecasts, thus increasing people's awareness of the increased risks of outdoor falls on days when the prognoses fit the described high-risk combinations of weather conditions. For example, regional agencies for civil defense and emergencies in Russia inform people by short message service (SMS) about inclement weather, like strong winds and snowstorms. Based on the results of this study and local weather forecasts, SMS warnings about the higher risks of outdoor falls may also become an effective AOFI prevention tool. Such messages may also support local decision making with respect to the timely initiation of snow and ice removal and the application of anti-friction materials on walkways.

The strengths of this study are its population-based design and the geographically defined area. Given the weather and other environmental and socioeconomic contexts in the Shenkursk District are similar to those of other rural settings in Northern Russia and in other northern countries, our findings may be applicable beyond the study area. Another strength is the use of data from a registry with high coverage and representativeness of the total injuries in the district [30]. Finally, we analyzed only AOFIs, while many other studies of seasonal variation in falls did not separate outdoor and indoor fall injuries, even though they have different characteristics $[3,17,18,53]$.

A possible limitation of our study is that the SHIR included only AOFIs that were medically treated at the $\mathrm{CDH}$. Therefore, our results may be less applicable to people with mild AOFI who did not seek medical care. 
In this study, we analyzed AOFIs without stratification by sex and age, although some variation in the effect of weather conditions on the incidence of AOFIs is possible by age and sex. This study should be replicated either in a larger population or over a longer period in order to obtain a more detailed age- and sex-specific analysis.

As the study has an ecological design, the outcome variable in our analyses was the daily number of AFOIs, and a calendar day was the unit of observation. This design did not allow us to control for possible behavioral factors on an individual level, e.g., alcohol consumption [54,55]. We tried testing and saw no association between the weekend variable (Saturday and Sunday vs. weekdays) as a proxy for alcohol consumption and the number of AOFIs. Moreover, factors like alcohol consumption are unlikely to be associated with the weather conditions that we identified as being associated with AOFIs. Therefore, confounding from alcohol consumption is unlikely.

\section{Conclusions}

The AOFIs in the Shenkursk District occurred more often in the cold season than in the warm season. A combination of low air temperature, medium/high precipitation, and a ground surface covered with compact or wet snow were the attributes of days with higher risks of AOFIs in the cold season. In the warm season, the numbers of AOFIs were higher on days with medium air temperature and atmospheric pressure. Larger-scale future research is required to study the impacts of weather conditions on the frequency of AOFIs by age and sex.

Author Contributions: Conceptualization, T.N.U., A.M.G., T.A.T., B.Y. and A.V.K.; Formal analysis, T.N.U. and A.V.K.; Investigation, T.N.U., A.M.G. and A.V.K.; Methodology, T.N.U., A.M.G., T.A.T., B.Y. and A.V.K.; Visualization, T.N.U.; Writing-Original Draft Preparation, T.N.U. and A.V.K.; Writing-Review \& Editing, A.M.G., T.A.T., B.Y.; Supervision, A.V.K. All authors have read and agreed to the published version of the manuscript.

Funding: Establishment of the SHIR and data collection in 2015-2017 was supported by a grant of Norwegian Ministry of Health and Care Services. PhD scholarship and operational funds of the first author are provided by the Arctic Health Research group at the Department of Community Medicine, UiT. The publication charges for this article have been funded by a grant from the publication fund of UiT The Arctic University of Norway.

Acknowledgments: Our thanks to Chief physician of Shenkursk central district hospital Vassili Anfimov and the Mayor of Shenkursk Irina Pitolina for their support in implementing the Shenkursk Injury Registry, the injury registrars, the hospital staff, and all patients who participated in the study.

Conflicts of Interest: The authors declare no conflict of interest.

Ethics Approval and Consent to Participate: The establishment of the SHIR and the corresponding data collection were approved by the Ethics Committee of the Northern State Medical University, Arkhangelsk (protocol 07/10-13 from 09.10.2013). Both medical and nonmedical information were collected by the Shenkursk central district hospital, which holds the rights to do so through local regulations and informed consent. The protocol for the present study was approved by the Ethics Committee of the Northern State Medical University, Arkhangelsk (protocol 03/04-17 from 27.04.2017). The study has been evaluated by the Norwegian Regional Committees for Medical and Health Research Ethics (49) (Remit Assessment 2017/1995/REK nord).

\section{References}

1. Chow, K.P.; Fong, D.Y.T.; Wang, M.P.; Wong, J.Y.H.; Chau, P.H. Meteorological factors to fall: A systematic review. Int. J. Biometeorol. 2018, 62, 2073-2088. [CrossRef] [PubMed]

2. Gyllencreutz, L.; Björnstig, J.; Rolfsman, E.; Saveman, B.-I. Outdoor pedestrian fall-related injuries among Swedish senior citizens-injuries and preventive strategies. Scand. J. Caring Sci. 2015, 29, 225-233. [CrossRef] [PubMed]

3. Flinkkilä, T.; Sirniö, K.; Hippi, M.; Hartonen, S.; Ruuhela, R.; Ohtonen, P.; Hyvönen, P.; Leppilahti, J. Epidemiology and seasonal variation of distal radius fractures in Oulu, Finland. Osteoporos. Int. 2011, 22, 2307-2312. [CrossRef] [PubMed]

4. Health for All (HFA) Family of Databases. Available online: https://gateway.euro.who.int/en/hfa-explorer/ (accessed on 10 January 2020). 
5. World Health Organization. Global Health Estimates 2016: Deaths by Cause, Age, Sex, by Country and by Region, 2000-2016. Available online: https://www.who.int/healthinfo/global_burden_disease/estimates/en (accessed on 10 January 2020).

6. Stevens, J.A.; Thomas, K.E.; Sogolow, E.D. Seasonal patterns of fatal and nonfatal falls among older adults in the U.S. Accid. Anal. Prev. 2007, 39, 1239-1244. [CrossRef] [PubMed]

7. James, M.K.; Victor, M.C.; Saghir, S.M.; Gentile, P.A. Characterization of fall patients: Does age matter? J. Saf. Res. 2018, 64, 83-92. [CrossRef] [PubMed]

8. Burns, E.R.; Stevens, J.A.; Lee, R. The direct costs of fatal and non-fatal falls among older adults-United States. J. Saf. Res. 2016, 58, 99-103. [CrossRef]

9. Bergland, A.; Jarnlo, G.-B.; Laake, K. Predictors of falls in the elderly by location. Aging Clin. Exp. Res. 2003, 15, 43-50. [CrossRef]

10. Bath, P.A.; Morgan, K. Differential risk factor profiles for indoor and outdoor falls in older people living at home in Nottingham, UK. Eur. J. Epidemiol. 1999, 15, 65-73. [CrossRef]

11. Li, W.; Keegan, T.H.M.; Sternfeld, B.; Sidney, S.; Quesenberry, C.P., Jr.; Kelsey, J.L. Outdoor falls among middle-aged and older adults: A neglected public health problem. Am. J. Public Health 2006, 96, 1192-1200. [CrossRef]

12. Weinberg, L.E.; Strain, L.A. Community-dwelling older adults' attributions about falls. Arch. Phys. Med. Rehabil. 1995, 76, 955-960. [CrossRef]

13. Björnstig, U.; Björnstig, J.; Dahlgren, A. Slipping on ice and snow_Elderly women and young men are typical victims. Accid. Anal. Prev. 1997, 29, 211-215. [CrossRef]

14. Kelsey, J.L.; Berry, S.D.; Procter-Gray, E.; Quach, L.; Nguyen, U.-S.D.T.; Li, W.; Kiel, D.P.; Lipsitz, L.A.; Hannan, M.T. Indoor and outdoor falls in older adults are different: The maintenance of balance, independent living, intellect, and Zest in the Elderly of Boston Study. J. Am. Geriatr. Soc. 2010, 58, 2135-2141. [CrossRef]

15. Schepers, P.; den Brinker, B.; Methorst, R.; Helbich, M. Pedestrian falls: A review of the literature and future research directions. J. Saf. Res. 2017, 62, 227-234. [CrossRef] [PubMed]

16. Gao, C.; Holmér, I.; Abeysekera, J. Slips and falls in a cold climate: Underfoot surface, footwear design and worker preferences for preventive measures. Appl. Ergon. 2008, 39, 385-391. [CrossRef] [PubMed]

17. Bulajic-Kopjar, M. Seasonal variations in incidence of fractures among elderly people. Inj. Prev. 2000, 6, 16-19. [CrossRef] [PubMed]

18. Modarres, R.; Ouarda, T.B.M.J.; Vanasse, A.; Orzanco, M.G.; Gosselin, P. Modeling seasonal variation of hip fracture in Montreal, Canada. Bone 2012, 50, 909-916. [CrossRef]

19. Lin, L.-W.; Lin, H.-Y.; Hsu, C.-Y.; Rau, H.-H.; Chen, P.-L. Effect of weather and time on trauma events determined using emergency medical service registry data. Injury 2015, 46, 1814-1820. [CrossRef]

20. Mazzucchelli, R.; Crespí-Villarías, N.; Pérez-Fernández, E.; Durbán Reguera, M.L.; Guzón Illescas, O.; Quirós, J.; García-Vadillo, A.; Carmona, L.; Rodriguez-Caravaca, G.; Gil de Miguel, A. Weather conditions and their effect on seasonality of incident osteoporotic hip fracture. Arch. Osteoporos. 2018, 13, 28. [CrossRef]

21. Mardani-Kivi, M.; Karimi-Mobarakeh, M.; Kazemnejad, E.; Saheb-Ekhtiari, K.; Hashemi-Motlagh, K. Snow Catastrophe Conditions: What is its Impact on Orthopedic Injuries? Arch. Bone Jt. Surg. 2014, 2, 111-113.

22. Yeung, P.-Y.; Chau, P.-H.; Woo, J.; Yim, V.W.-T.; Rainer, T.H. Higher incidence of falls in winter among older people in Hong Kong. J. Clin. Gerontol. Geriatr. 2011, 2, 13-16. [CrossRef]

23. Gao, C.; Abeysekera, J. Slips and falls on ice and snow in relation to experience in winter climate and winter sport. Saf. Sci. 2004, 42, 537-545. [CrossRef]

24. Lépy, É.; Rantala, S.; Huusko, A.; Nieminen, P.; Hippi, M.; Rautio, A. Role of Winter Weather Conditions and Slipperiness on Tourists' Accidents in Finland. Int. J. Environ. Res. Public Health 2016, 13, 822. [CrossRef] [PubMed]

25. Morency, P.; Voyer, C.; Burrows, S.; Goudreau, S. Outdoor falls in an urban context: Winter weather impacts and geographical variations. Can. J. Public Health 2012, 103, 218-222. [CrossRef] [PubMed]

26. WHO. Global Report on Falls Prevention in Older Age; World Health Organization: Geneva, Switzerland, 2007.

27. Population distribution of the Arkhangelsk region by sex and age on 1 January 2015. In Statistical Handbook; Arkhangelskstat: Arkhangelsk, Russia, 2015.

28. Population distribution of the Arkhangelsk region by sex and age on 1 January 2018. In Statistical Handbook; Arkhangelskstat: Arkhangelsk, Russia, 2018.

29. Shenkursk. Climate. Available online: https://en.wikipedia.org/wiki/Shenkursk (accessed on 30 July 2020). 
30. Unguryanu, T.N.; Grjibovski, A.M.; Trovik, T.A.; Ytterstad, B.; Kudryavtsev, A.V. Injury registration for primary prevention in a provincial Russian region: Setting up a new trauma registry. Scand. J. Trauma Resusc. Emerg. Med. 2019, 27, 47. [CrossRef]

31. Unguryanu, T.N.; Kudryavtsev, A.V.; Anfimov, V.G.; Ytterstad, B.; Grjibovski, A.M. The first population-based registry in Russia: Establishment, logistics and role in the municipal injury prevention programme. Ekol. Cheloveka (Hum. Ecol.) 2017, 56-64. [CrossRef]

32. Weather Archive in Shenkursk. Available online: https://rp5.ru/Weather_archive_in_Shenkursk (accessed on 15 June 2019).

33. Long, S.; Freese, J. Regression Models for Categorical Dependent Variables Using Stata; Stata Press: College Station, TX, USA, 2014.

34. Atherton, W.G.; Harper, W.M.; Abrams, K.R. A year's trauma admissions and the effect of the weather. Injury 2005, 36, 40-46. [CrossRef]

35. Luukinen, H.; Koski, K.; Kivelä, S.L. The relationship between outdoor temperature and the frequency of falls among the elderly in Finland. J. Epidemiol. Community Health 1996, 50, 107. [CrossRef]

36. Grønskag, A.B.; Forsmo, S.; Romundstad, P.; Langhammer, A.; Schei, B. Incidence and seasonal variation in hip fracture incidence among elderly women in Norway. The HUNT Study. Bone 2010, 46, 1294-1298. [CrossRef]

37. Bischoff-Ferrari, H.A.; Dawson-Hughes, B.; Willett, W.C.; Staehelin, H.B.; Bazemore, M.G.; Zee, R.Y.; Wong, J.B. Effect of Vitamin D on falls: A meta-analysis. JAMA 2004, 291, 1999-2006. [CrossRef]

38. Pasco, J.A.; Henry, M.J.; Kotowicz, M.A.; Sanders, K.M.; Seeman, E.; Pasco, J.R.; Schneider, H.G.; Nicholson, G.C. Seasonal periodicity of serum vitamin D and parathyroid hormone, bone resorption, and fractures: The Geelong Osteoporosis Study. J. Bone Miner. Res. 2004, 19, 752-758. [CrossRef]

39. Malyavskaya, S.I.; Kostrova, G.N.; Lebedev, A.V.; Golysheva, E.V.; Karamyan, V.G. 25(OH)D levels in the population of Arkhangelsk city in different age groups. Ekol. Cheloveka (Hum. Ecol.) 2018, 60-64. [CrossRef]

40. Bischoff-Ferrari, H.A. Should vitamin D administration for fracture prevention be continued? A discussion of recent meta-analysis findings. Z. Gerontol. Geriatr. 2019, 52, 428-432. [CrossRef] [PubMed]

41. Bolland, M.J.; Grey, A.; Avenell, A. Effects of vitamin D supplementation on musculoskeletal health: A systematic review, meta-analysis, and trial sequential analysis. Lancet Diabetes Endocrinol. 2018, 6, 847-858. [CrossRef]

42. Bischoff-Ferrari, H.A.; Orav, E.J.; Abderhalden, L.; Dawson-Hughes, B.; Willett, W.C. Vitamin D supplementation and musculoskeletal health. Lancet Diabetes Endocrinol. 2019, 7, 85. [CrossRef]

43. De Koning, J.J.; de Groot, G.; van Ingen Schenau, G.J. Ice friction during speed skating. J. Biomech. 1992, 25, 565-571. [CrossRef]

44. Gao, C.; Abeysekera, J. A systems perspective of slip and fall accidents on icy and snowy surfaces. Ergonomics 2004, 47, 573-598. [CrossRef]

45. Ytterstad, B. The Harstad injury prevention study: Community based prevention of fall-fractures in the elderly evaluated by means of a hospital based injury recording system in Norway. J. Epidemiol. Community Health 1996, 50, 551-558. [CrossRef] [PubMed]

46. Gevitz, K.; Madera, R.; Newbern, C.; Lojo, J.; Johnson, C.C. Risk of Fall-Related Injury due to Adverse Weather Events, Philadelphia, Pennsylvania, 2006-2011. Public Health Rep. 2017, 132, 53s-58s. [CrossRef] [PubMed]

47. Von Mackensen, S.; Hoeppe, P.; Maarouf, A.; Tourigny, P.; Nowak, D. Prevalence of weather sensitivity in Germany and Canada. Int. J. Biometeorol. 2005, 49, 156-166. [CrossRef]

48. Kimoto, K.; Aiba, S.; Takashima, R.; Suzuki, K.; Takekawa, H.; Watanabe, Y.; Tatsumoto, M.; Hirata, K. Influence of Barometric Pressure in Patients with Migraine Headache. Intern. Med. 2011, 50, 1923-1928. [CrossRef]

49. Kamiński, M.; Cieślik-Guerra, U.I.; Kotas, R.; Mazur, P.; Marańda, W.; Piotrowicz, M.; Sakowicz, B.; Napieralski, A.; Trzos, E.; Uznańska-Loch, B.; et al. Evaluation of the impact of atmospheric pressure in different seasons on blood pressure in patients with arterial hypertension. Int. J. Occup. Med. Environ. Health 2016, 29, 783-792. [CrossRef] [PubMed]

50. Peeters, G.; Cooper, R.; Tooth, L.; van Schoor, N.M.; Kenny, R.A. A comprehensive assessment of risk factors for falls in middle-aged adults: Co-ordinated analyses of cohort studies in four countries. Osteoporos. Int. 2019, 30, 2099-2117. [CrossRef] [PubMed] 
51. McKiernan, F.E. A simple gait-stabilizing device reduces outdoor falls and nonserious injurious falls in fall-prone older people during the winter. J. Am. Geriatr. Soc. 2005, 53, 943-947. [CrossRef] [PubMed]

52. Berggård, G.; Johansson, C. Pedestrians in wintertime-effects of using anti-slip devices. Accid. Anal. Prev. 2010, 42, 1199-1204. [CrossRef]

53. Turner, R.M.; Hayen, A.; Dunsmuir, W.T.M.; Finch, C.F. Air temperature and the incidence of fall-related hip fracture hospitalisations in older people. Osteoporos. Int. 2011, 22, 1183-1189. [CrossRef]

54. Kholmatova, K.K.; Gribovski, A.M. Ecological studies in medicine and public health. Ekol. Cheloveka (Hum. Ecol.) 2016, 57-64. [CrossRef]

55. Morgenstern, H. Ecologic studies in epidemiology: Concepts, principles, and methods. Annu. Rev. Public Health 1995, 16, 61-81. [CrossRef]

(C) 2020 by the authors. Licensee MDPI, Basel, Switzerland. This article is an open access article distributed under the terms and conditions of the Creative Commons Attribution (CC BY) license (http://creativecommons.org/licenses/by/4.0/). 